\title{
A comparison of measured HONO uptake and release with calculated source strengths in a heterogeneous forest environment
}

M. Sörgel et al.

Correspondence to: M. Sörgel (m.soergel@mpic.de) 


\section{$1 \quad 1$ Site description}

3 A detailed description of the research area and measurement sites can be found in Gerstberger

4 et al. (2004), Staudt and Foken (2007) and Foken et al. (2012). A detailed description of the

5 clearing site and the intensive campaign EGER IOP-3 can be found in Serafimovich et al.

6 (2011). Figure S1 shows the heterogeneity of the area and the three measurements sites.

7

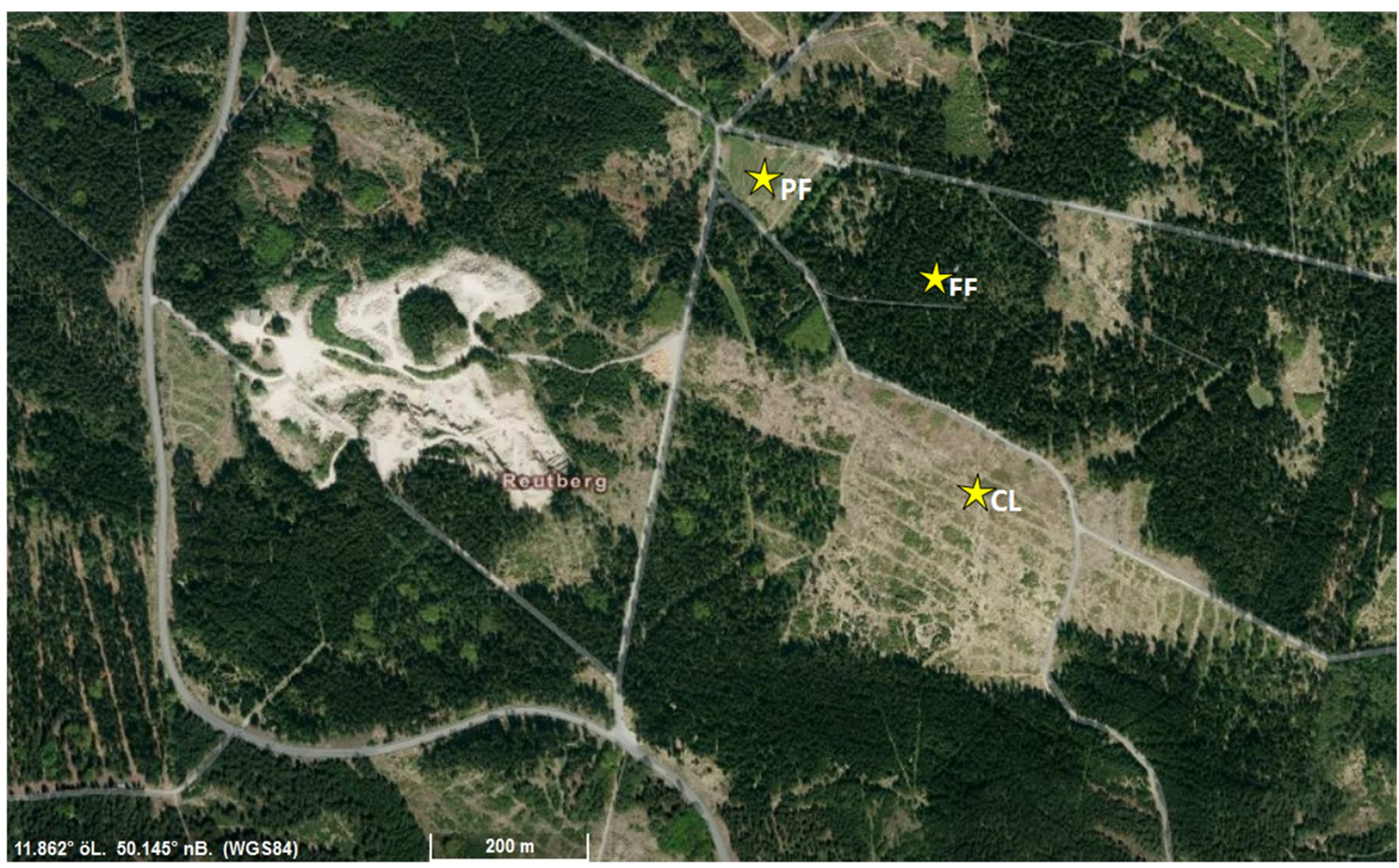

9 Figure S1: Aerial view (data source: Bayerische Vermessungsverwaltung - www.geodaten.bayern.de) of the 10 measurement sites shows the heterogeneous forest landscape of the research area with the marked sites forest 11 floor (FF), clearing (CL) and "Pflanzgarten" (PF). The white area on the left side of the picture is a stone pit. 12 Most roads are forest roads except the curvy road running from the middle of the bottom of the picture to the 13 upper left corner (i.e. from the south to the north-west of the measurement sites). This road is a country road with 14 about 2100 cars per working day (Foken et al., 2012). The clearing has the dimensions of $\sim 300 \mathrm{x} 400 \mathrm{~m}$.

\section{Lift system}

18 Figure S2 shows the lift system used for sampling at different heights. The system consists of 19 a vertical linear guide system (Igus, Cologne, Germany) and a stepper motor with a custom 20 built control unit (electronics workshop, University of Bayreuth). The heights are 21 programmable and ranged between $0.1 \mathrm{~m}$ above ground level to $1.6 \mathrm{~m}$ above ground level. 


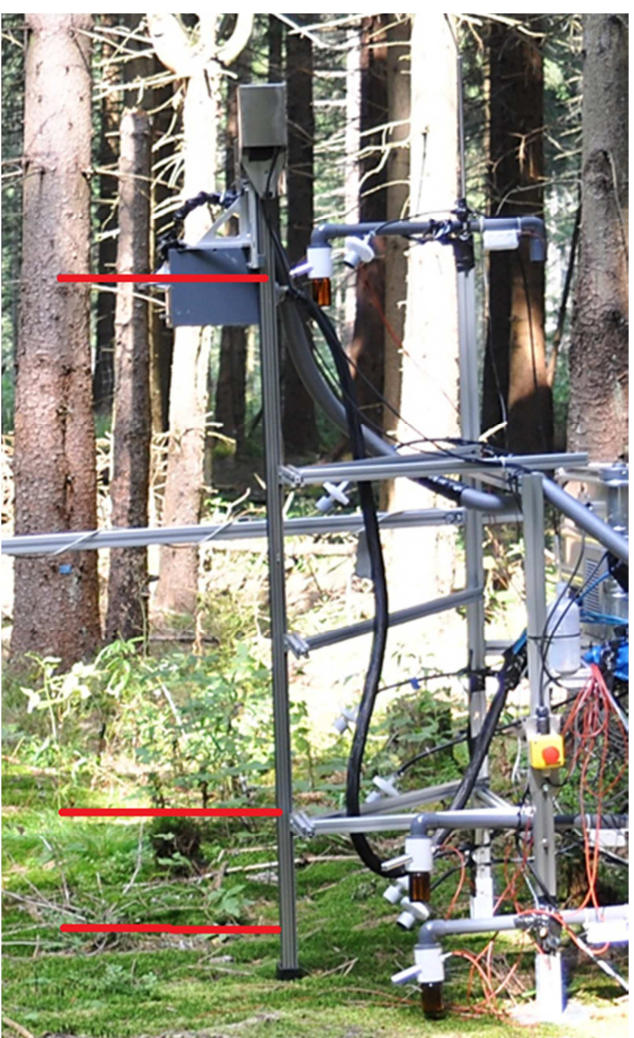

2 Figure S2: External sampling unit of the LOPAP (grey box) and inlet for $\mathrm{NO}_{\mathrm{x}}$ installed on the lift system at the 3 forest floor. Three positions $(1.6 \mathrm{~m}, 0.4 \mathrm{~m}$ and $0.1 \mathrm{~m})$ used for the profile measurements are indicated in red.

\section{Laboratory measurements of soil fluxes}

8 In order to evaluate potential soil HONO emissions, several soil samples were taken from the sites where the lift system was located. The soil type is classified as haplic podzol over granite bedrock (Gerstberger et al., 2004) for this area, but only the soil organic layer (O horizon) was sampled. This organic layer is characterized by a high water holding capacity and very low pH values (Gerstberger et al., 2004). On 30 Aug 2012, the first soil sample (Sample 1) was taken from a hemicycle with a radius of about $10 \mathrm{~m}$ around the lift system.

14 The green moss on top of the soil $(0.8-1.5 \mathrm{~cm})$ was removed, and the Oe and Oa horizons were sampled separately in three replicates. These samples were transported on ice in a cooling box to the laboratory. The Oe soil sample was measured immediately after sampling, and the Oa soil sample was stored in a refrigerator for $24 \mathrm{~h}$ at $4{ }^{\circ} \mathrm{C}$ before measurement. For samples 2-4, which were taken on 11 June 2013, the vegetation cover was removed and the upper $5 \mathrm{~cm}$ of the $\mathrm{O}$ horizon was sampled by sampling rings. Three sampling rings have been 
1 taken for one subsample. These samples were transported in a cooling box for about $10 \mathrm{~h}$ and 2 then stored at $4{ }^{\circ} \mathrm{C}$ in a refrigerator prior to analysis within the following 3 to 5 days. For each 3 site (forest/clearing) we chose two different types of understory vegetation for sampling. In 4 the forest, the soil was covered by moss (Sample 1). As a prior study found higher NO 5 emissions for blueberry than for moss in that respective forest patch (Bargsten et al. 2010), we 6 also sampled a stand of blueberries nearby (Sample 2). At the clearing, the understory close to 7 the lift system consisted mainly of grass and some small blueberry plants (Sample 4). We also 8 took soil samples from the surrounding, which was dominated by blueberries on moist soil 9 (Sample 3).
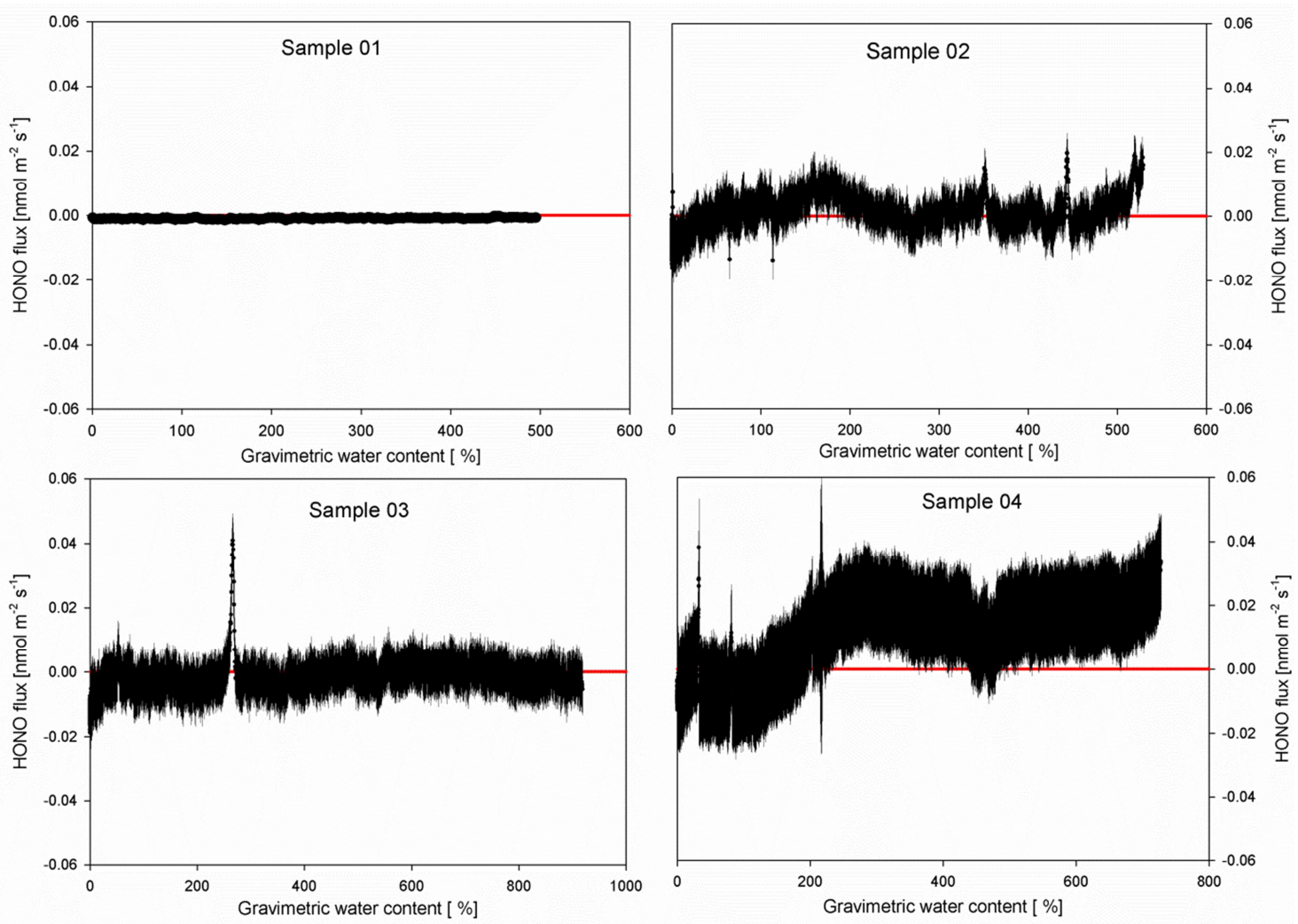

Figure S3: HONO fluxes from four different soil samples measured in a dynamic laboratory chamber according to Oswald et al. (2013). Sample 1 was taken from the forest floor covered with moss, whereas for sample 2 the ground was covered by blueberries. Samples 3 and 4 were taken on the clearing from moist soil covered by blueberries and from ground covered by grass, respectively. The differences in the errors are due to different detection limits $(0.5 \mathrm{ppt}$ to $6 \mathrm{ppt})$ for the LOPAP instrument.

For each understory type, three subsamples were taken. These have been combined into one sample which was measured in the laboratory system. The laboratory setup to measure the emission fluxes was described in detail elsewhere (Oswald et al., 2013, Wu et al., 2014). Briefly, the soil samples were passed through $16 \mathrm{~mm}$ sieves (instead of $2 \mathrm{~mm}$ ), reducing the 
1 influence of the destruction of the structure of soil organic matter on trace gas emission 2 (Bargsten et al., 2010). Roots were removed to the extent possible, $50 \mathrm{~g}$ of soil were put in a 3 petri dish $\left(\mathrm{OD}=88 \mathrm{~mm}\right.$ ), and purified water (resistivity $18.2 \mathrm{M} \Omega \mathrm{cm}^{-1}$ ) was added to reach 4 water holding capacity. The dish was placed in a Teflon chamber (47 L) within a climate 5 cabinet at $15{ }^{\circ} \mathrm{C}$ for Sample 1 and $25{ }^{\circ} \mathrm{C}$ for samples 2-4. The chamber was flushed with $8 \mathrm{~L}$ $6 \mathrm{~min}^{-1}$ of dry purified air, and the trace gas mixing ratios ( $\mathrm{NO}, \mathrm{NO}_{2}, \mathrm{O}_{3}, \mathrm{CO}_{2}, \mathrm{H}_{2} \mathrm{O}$ and $\mathrm{HONO}$ ) 7 were monitored in the chamber outflow. $\mathrm{NO}_{\mathrm{x}}$ was measured by chemiluminescence (Model 42i-TL Thermo Scientific, Franklin, MA, USA), ozone by UV-absorption (Model 49iThermo Scientific, Franklin, MA, USA), $\mathrm{CO}_{2}$ and $\mathrm{H}_{2} \mathrm{O}$ by infrared absorption (Model 840A, LI-COR, Lincoln, Nebraska, USA), and HONO was measured by long path absorption (LOPAP-03, QUMA Elektronik \& Analytik GmbH, Wuppertal, Germany). The least sensitive detection limit of the LOPAP was $6 \mathrm{ppt}$, and the resulting minimum detectable flux was $0.004 \mathrm{nmol} \mathrm{m}^{-2}$ $\mathrm{s}^{-1}$. The detection limit for NO was $50 \mathrm{ppt}$, and the minimum detectable flux was $0.04 \mathrm{nmol}$ $\mathrm{m}^{-2} \mathrm{~s}^{-1}$. The uncertainties of the fluxes were calculated using Gaussian error propagation according to Oswald et al. (2013). The gravimetric soil water content during the laboratory soil measurements was calculated from the loss of water using the water vapor measurements in the sample air (see Oswald et al. 2013). Soil properties were analyzed according to standard procedures: $\mathrm{pH}$ was measured according to DIN ISO 10390 in a $0.0125 \mathrm{~mol} \mathrm{l}^{-1} \mathrm{CaCl}_{2}$ solution. Mineral nitrogen (ammonia, nitrite, nitrate) was measured according to DIN ISO/TS $14256-1$ in a $0.0125 \mathrm{~mol} \mathrm{l}^{-1} \mathrm{CaCl}_{2}$ extract with photometric detection of nitrite after reduction of nitrate to nitrite.

Table S1: Soil pH and nutrient content $\left(\mathrm{NH}_{4}{ }^{+} ; \mathrm{NO}_{2}^{-}\right.$and $\left.\mathrm{NO}_{3}{ }^{-}\right)$for the measured samples in comparison to previously published values (Bargsten et al., 2010 and Gerstberger et al., 2004). * pH values measured by $\mathrm{pH}$ electrode in soil solution (water).

\begin{tabular}{lcccc}
\hline $\begin{array}{l}\text { Sample } \\
\text { bm = before measurement } \\
\text { am = after measurement }\end{array}$ & $\begin{array}{c}\mathbf{p H} \\
-\end{array}$ & $\begin{array}{c}\mathbf{N H}_{\mathbf{4}}-\mathbf{N} \\
{[\mathrm{mg} / \mathrm{kg}]}\end{array}$ & $\begin{array}{c}\mathbf{N O}_{2}-\mathbf{N} \\
{[\mathrm{mg} / \mathrm{kg}]}\end{array}$ & $\begin{array}{c}\mathbf{N O}_{\mathbf{3}}-\mathbf{N} \\
{[\mathrm{mg} / \mathrm{kg}]}\end{array}$ \\
\hline \hline This study & & & & \\
Sample 1 (bm) & 3.2 & 239.6 & 0.35 & 36.9 \\
Sample 2 (bm) & 3.4 & 49.7 & 0.50 & 5.0 \\
Sample 2 (am) & 3.4 & 6.3 & 0.33 & 2.3 \\
Sample 3 (bm) & 3.1 & 29.2 & 0.89 & 4.9 \\
Sample 3 (am) & 2.9 & 19.4 & 0.13 & 1.7 \\
Sample 4 (bm) & 3.0 & 36.7 & 0.99 & 12.9 \\
Sample 4 (am) & 2.8 & 16.8 & 0.12 & 3.4 \\
Sample 4 (am) replicate & 2.8 & 17.9 & 0.13 & 3.3 \\
Mean (bm) & $\mathbf{3 . 2}$ & $\mathbf{3 8 . 5}$ & $\mathbf{0 . 7 9}$ & $\mathbf{7 . 6}$ \\
\hline Bargst
\end{tabular}

Bargsten et al. (2010) 
M1 (moss)

M2 (moss)

G1 (grass)

G2 (grass)

S1 (spruce)

S2 (spruce)

B1 (blueberry)

B2 (blueberry)

Mean

Gerstberger et al. (2004)

$\mathrm{pH}$ in water Oi horizon

$\mathrm{pH}$ in $\mathrm{CaCl}_{2}$ Oi horizon

$\mathrm{pH}$ in water Oe horizon

$\mathrm{pH}$ in $\mathrm{CaCl}_{2}$ Oe horizon

$\mathrm{pH}$ in water $\mathrm{Oa}$ horizon

$\mathrm{pH}$ in water Oa horizon $\begin{array}{cc}4.6^{*} & 194 \\ 5^{*} & 148\end{array}$

4.1* 207

3.6* 204

$3.5^{*} \quad 56$

$3.5^{*} \quad 86$

$4.7 * \quad 139$

$3.7^{*} \quad 148$

4.1* 148

$4.5^{*}$

3.6

$3.8^{*}$

2.9

$3.5^{*}$

2.6

$\begin{array}{cc}- & 2 \\ - & 7 \\ - & 1 \\ - & 2 \\ - & 11 \\ - & 1 \\ - & 1 \\ - & 2 \\ - & 3.4\end{array}$

3.4

2

$34 \quad \mathrm{HNO}_{3}$ photolysis

4

5 We determined the nitrate loading of three spruce trees (Samples 1-19, Table S2) at the 6 clearing site by foliar rinsing, a method previously used to determine $\mathrm{HNO}_{3}$ deposition fluxes.

7 It was shown that nitrate recovery rates are generally better than $90 \%$ for this method (e.g.

$8 \quad$ Marshall and Cadle, 1989; Cadle et al., 1991).

9 Nitrate was washed off the needles using purified water (18 $\mathrm{M} \Omega)$ by exposing a branch length

10 of about $8 \mathrm{~cm}$ to $20 \mathrm{ml}$ purified water in a $40 \mathrm{ml}$ polyethylene flask, and swirling the flask for

112 min to assure mixing in the solution and wetting of all parts of the branch. The solution was

12 measured by ion chromatography (Central Analytical Laboratory, University of Bayreuth).

13 The amount of measured nitrate was then normalized to the total needle area, which was

14 determined by harvesting the branch, separating all needles and taking photographs of the

15 needles on a white background containing a scale. These pictures were converted to black and

16 white pictures. By measuring the pixels of the scale, the number of dark pixels (projected

17 needle area) was converted to the needle area (in $\mathrm{cm}^{2}$ ).

18

19 Table S2: Measured leaf nitrate and needle areas of small spruce trees at the clearing site.

\begin{tabular}{lccccc}
\hline Sample & $\begin{array}{c}\text { Time of day } \\
\text { (CET) }\end{array}$ & $\mathrm{NO}_{3}^{-}$ & $\mathrm{NO}_{3}^{-}$ & $\begin{array}{c}\text { Projected } \\
\text { needle area } \\
\mathrm{cm}^{3}\end{array}$ & $\begin{array}{c}\text { Geometric } \\
\text { needle area } \\
\mathrm{cm}^{3}\end{array}$ \\
\hline \hline 1 (tree 1) & $16: 00$ & $\mathrm{mg} \mathrm{l}^{-1}$ & $\mathrm{~mol}$ & 17.2 & 45.5 \\
2 (tree 1) & $16: 00$ & 0.12 & $3.87 \mathrm{E}-08$ & 12.7 & 33.8 \\
6 & & & & &
\end{tabular}




\begin{tabular}{|c|c|c|c|c|c|}
\hline 3 (tree 2) & $16: 00$ & 0.09 & $2.90 \mathrm{E}-08$ & 11.7 & 31.0 \\
\hline $4($ tree 2$)$ & $16: 00$ & 0.04 & $1.29 \mathrm{E}-08$ & 12.0 & 31.7 \\
\hline $5($ tree 3$)$ & $16: 00$ & 0.05 & $1.61 \mathrm{E}-08$ & 21.1 & 56.0 \\
\hline $6($ tree 1$)$ & $18: 15$ & 0.06 & $1.94 \mathrm{E}-08$ & 14.7 & 38.8 \\
\hline $7($ tree 1$)$ & $18: 15$ & 0.10 & $3.23 \mathrm{E}-08$ & 18.9 & 50.1 \\
\hline $8($ tree 2$)$ & $18: 15$ & $<$ & & 16.3 & 43.2 \\
\hline $9($ tree 2$)$ & $18: 15$ & 0.09 & $2.90 \mathrm{E}-08$ & 16.9 & 44.8 \\
\hline $10($ tree 3$)$ & $18: 15$ & 0.04 & $1.29 \mathrm{E}-08$ & 12.1 & 32.1 \\
\hline 11 (tree 1$)$ & 20.15 & 0.10 & $3.23 \mathrm{E}-08$ & 17.8 & 47.3 \\
\hline $12($ tree 1$)$ & 20.15 & 0.08 & $2.58 \mathrm{E}-08$ & 23.4 & 62.1 \\
\hline 13 (tree 2$)$ & 20.15 & 0.08 & $2.58 \mathrm{E}-08$ & 19.7 & 52.2 \\
\hline 14 (tree 2) & 20.15 & 0.06 & $1.94 \mathrm{E}-08$ & 16.0 & 42.5 \\
\hline 15 (tree 3$)$ & 20.15 & $<$ & & 12.1 & 32.2 \\
\hline 16 (tree 2) & $22: 00$ & 0.09 & $2.90 \mathrm{E}-08$ & 16.0 & 42.5 \\
\hline $17($ tree 1$)$ & $22: 00$ & 0.09 & $2.90 \mathrm{E}-08$ & 14.5 & 38.3 \\
\hline 18 (tree 3$)$ & $22: 00$ & 0.11 & $3.55 \mathrm{E}-08$ & 19.7 & 52.2 \\
\hline 19 (tree 3$)$ & $22: 00$ & 0.13 & 4.19E-08 & 13.8 & 36.5 \\
\hline Mean & & 0.09 & 2.8E-08 & 16.1 & 42.8 \\
\hline $\begin{array}{l}\text { Standard } \\
\text { deviation }\end{array}$ & & $\mathbf{0 . 0 3}$ & 8.9E-09 & 3.4 & 9.0 \\
\hline
\end{tabular}

2

3 Additionally, three field blanks have been taken close to the institute building in Bayreuth, 4 where higher $\mathrm{HNO}_{3}$ levels are expected in the gas phase. The blank flasks were kept open to 5 the atmosphere for two minutes instead of being exposed to a branch. The field blanks were 6 below the detection limit of the method (i.e. $\left.<0.03 \mathrm{mg} \mathrm{L} \mathrm{L}^{-1} \mathrm{NO}_{3}^{-}\right)$. Nitrite $\left(\mathrm{NO}_{2}^{-}\right)$ 7 concentrations remained below the detection limit in all samples ( $\mathrm{LOD}=0.04 \mathrm{mg} \mathrm{L}^{-1} \mathrm{NO}_{2}^{-}$).

8 The measured nitrate loadings on the trees close to the institute building in Bayreuth (not 9 shown) were 3 to 20 times higher than the maximum values at the Waldstein site.

10 The advantage of the nondestructive method (i.e. not cutting the branches before washing 11 off), which can at least be applied to spruce trees, is that the branches can be marked and 12 sampled several times to establish time series using the same branches. Finally, the branches 13 can be harvested to measure the leaf area index (LAI). The error of the sampling area for the 14 repeated sampling should be low (a few needles more or less). It should be noted that neither 15 the method proposed by Zhou et al. (2011) nor our method discriminates between ammonium 16 nitrate and adsorbed nitric acid, which is supposed to be photolysed to finally yield HONO. 17 Thus the amount of adsorbed $\mathrm{HNO}_{3}$ might be overestimated.

18 The projected needle area can be converted to the total needle area by multiplying by a factor 19 of 2.65 derived by Oren et al. (1986). Thus, if $\mathrm{HNO}_{3}$ is distributed homogeneously on the 20 needle, the amount of $\mathrm{HNO}_{3}$ directly exposed to sunlight is a factor of 2.65 lower. If we then 
1 consider only the projected area of the whole branch with needles instead of the single 2 needles, the amount of $\mathrm{HNO}_{3}$ exposed is further reduced by a factor of 2.2 as derived from 3 our branch photographs.

4

\section{Nitrate loading of small spruce trees at clearing}

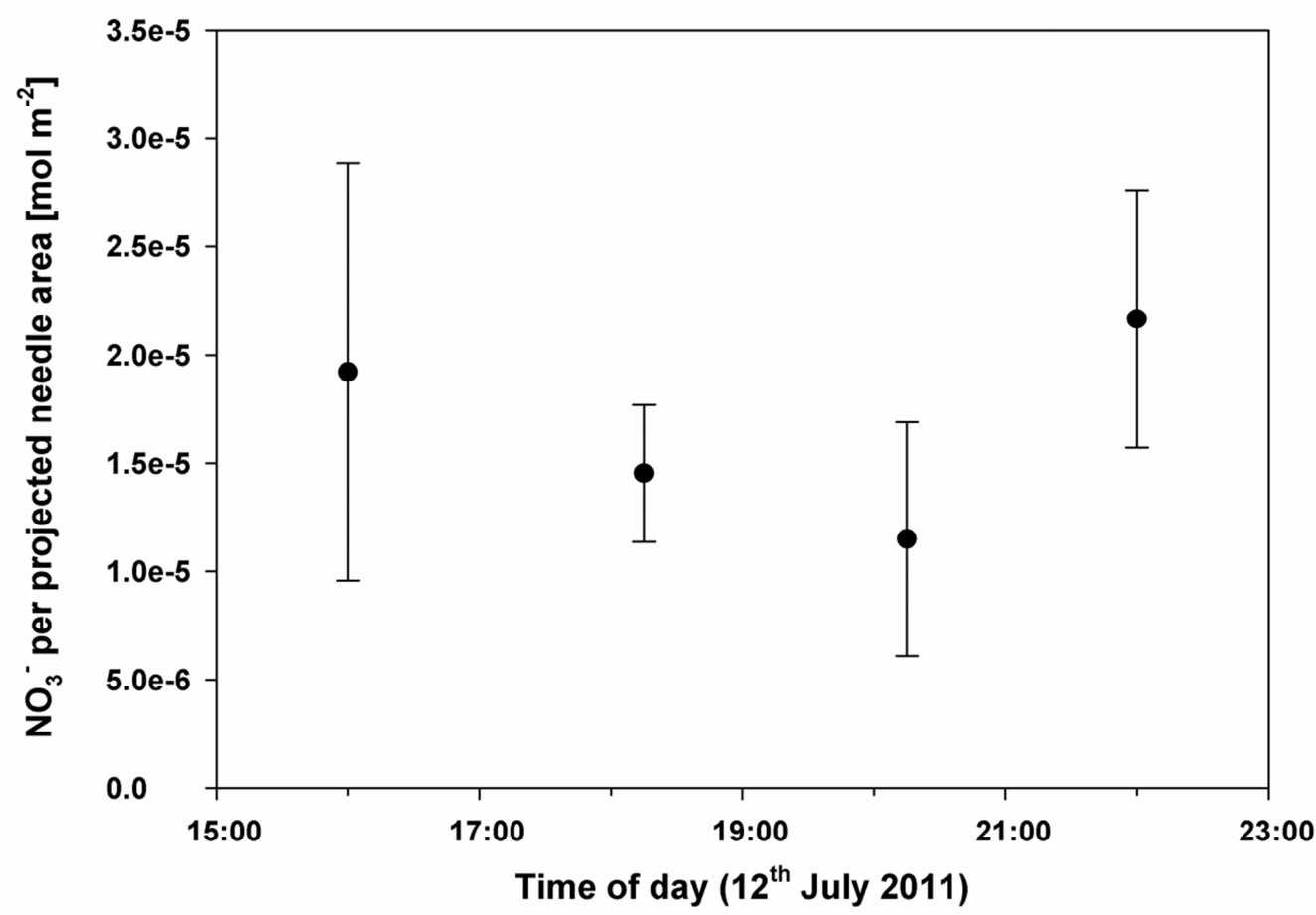

5

Figure S4: Calculated leaf nitrate loadings for 12 July 2011.

References:

Bargsten, A., Falge, E., Pritsch, K., Huwe, B., and Meixner, F. X.: Laboratory measurements of nitric oxide release from forest soil with a thick organic layer under different understory types, Biogeosciences, 7, 1425-1441, doi:10.5194/bg-7-1425-2010, 2010.

Foken, T., Meixner, F. X., Falge, E., Zetzsch, C., Serafimovich, A., Bargsten, A., Behrendt, T., Biermann, T., Breuninger, C., Dix, S., Gerken, T., Hunner, M., Lehmann-Pape, L., Hens, K., Jocher, G., Kesselmeier, J., Lüers, J., Mayer, J.-C., Moravek, A., Plake, D., Riederer, M., Rütz, F., Scheibe, M., Siebicke, L., Sörgel, M., Staudt, K., Trebs, I., Tsokankunku, A., Welling, M., Wolff, V., and Zhu, Z.: Coupling processes and exchange of energy and reactive and non-reactive trace gases at a forest site - results 
of the EGER experiment, Atmos. Chem. Phys., 12, 1923-1950, doi:10.5194/acp-121923-2012, 2012.

Gerstberger, P., Foken, T., and Kalbitz, K.: The Lehstenbach and Steinkreuz chatchments in NE Bavaria, Germany, in: Biogeochemistry of forested catchments in a changing environment, a german case study. Ecological Studies, edited by: Matzner, E., Springer, Heidelberg, 15-41, 2004.

Oren, R., Schulze, E.-D., Matyssek, R., and Zimmermann, R.: Estimating photosynthetic rate and annual carbon gain in conifers from specific leaf weight and leaf biomass, Oecologia, 70, 187- 193, 1986.

Serafimovich, A., Eder, F., Hübner, J., Falge, E., Voß, L., Sörgel, M., Held, A., Liu, Q., Eigenmann, R., Huber, K., Ferro Duarte, H., Werle, P., Gast, E., Cieslik, S., Heping, L. and Foken, T.: ExchanGE processes in mountainous Regions (EGER) documentation of the intensive observation period (IOP3) June, $13^{\text {th }}$ to July, $26^{\text {th }}$, 2011, Arbeitsergebnisse Nr. 47, Bayreuth, Germany, print ISSN 1614-8916; internet ISSN 1614-8924, 2011.

Staudt, K. and Foken, T.: Documentation of reference data for the experimental areas of the Bayreuth Centre for Ecology and Environmental Research (BayCEER) at the Waldstein site, Arbeitsergebn., Univ. Bayreuth, Abt. Mikrometeorol., ISSN: 161489166, 35, 35 pp., 2007.

Wu D., Kampf C. K., Pöschl U., Oswald R., Cui J., Ermel M., Hu C., Trebs I., and Sörgel M.: Novel tracer method to measure isotopic labeled gas-phase nitrous acid $\left(\mathrm{HO}^{15} \mathrm{NO}\right)$ in biogeochemical studies, Environmental Science \& Technology, 48, 8021-8027, 2014.

Zhou, X. L., Zhang, N., TerAvest, M., Tang, D., Hou, J., Bertman, S., Alaghmand, M., Shepson, P. B., Carroll, M. A., Griffith, S., Dusanter, S., and Stevens, P. S.: Nitric acid photolysis on forest canopy surface as a source for tropospheric nitrous acid, Nat. Geosci., 4, 440-443, 10.1038/ngeo1164, 2011. 